\title{
Policy Research in a Complex Context
}

\author{
Alessandro Colombo \\ Director of Research IReR - Lombardy Regional Institute for Research, Milan, Italy \\ E-mail: alessandro.colombo@irer.it \\ Received August 13, 2010; revised September 24, 2010; accepted October 29, 2010
}

\begin{abstract}
Today's world is characterized by uncertainty and complexity. While examining the importance of research in such a context, the paper attempts to outline a first definition of the role and potential of policy research. The policy process itself has become increasingly complex and non linear, as has its relationship with research. Consequently, policy researchers' contributions to policymakers may not have a direct, punctual and immediate influence on single issues, but rather a more pervasive, interactive, deliberative effect. Focusing on the theoretical definition of the risk, uncertainty and complexity of the policy process today, the paper outlines some questions and puts forward possible answers which offer a starting point for further analysis. It explores a new role for policy research and underlines the opportunities offered by argumentative, deliberative and multidisciplinary approaches which can positively impact democracy.
\end{abstract}

Keywords: Uncertainty, Complexity, Public Policy, Scientific Research, Policy Research, Policy Analysis, Scientific Advice

\section{Introduction}

The relationship between research—or scientists—and policy—or policymakers—has always been, and probably always will be, the subject of a permanent paradox. On one side, policymakers continually call for empirical data, evidence, facts, and authoritative explanations. Through almost all the steps of the policymaking process, they seek to justify the decisions they make on scientific grounds.

On the other hand, John M. Keynes' admonition stands the test of time and latitude: "there is nothing a government hates more than to be well-informed; for it makes the process of arriving at decisions much more complicated and difficult” [1].

Metaphorically there has always been an Aristotle at the court of every Alexander, and the two will always be linked together.

The origins of the policy focus on evidence are usually identified with the contribution of Harold Lasswell, considered to be the founder of policy sciences, and whose book The Policy Orientation (edited with Lerner) calls for the study of the role of "knowledge in and of the policy process" [2]. Following his pioneering studies, policy analysis became a field of interest, and is still progressing.
Caplan argues for a radical distinction between "two communities" which cannot communicate: researchers and policymakers "live in separate worlds, with different and often conflicting values, different rewards systems, and different languages" [3].

Others hold a less radical view, pointing out that "science has often played a major role in political decision processes, although much of the communication between scientists and policymakers has been limited to the scientists passing on scientific findings, leaving interpretation and judgement on relevance to policy processes for decision makers to decide" [4].

The role of scientific advice in the policy process has been interpreted in many ways. The earlier models simply differentiated between "technocratic" and "decisionist" forms of the nexus between science and policy [5]; the former being characterised by policy decisions depending on superior and well-informed knowledge provided by experts, and the latter giving primacy to politics over science. More recently, the dominant normative understanding tends to favour a more pragmatic and cooperative interaction. Carol Weiss empirically defines policy advice as a "diffuse process of enlightenment" in which policymakers are not influenced by any single study or report; instead policy advice has an impact on middle and long term changes of general problems, perceptions and world views [6]. 
Yet frequently "the fragmentation of responsibilities and decision-making across multiple bodies, piecemeal approaches to problems (...) and a failure to use science effectively" limit and undermine the relationship between research and policymaking [7]. Moreover, scientific research is only one of diverse sources of information and knowledge that is being brought into the policymaking process [8].

Following the rise of the evidence-based policy approach, many scholars reacted to its "empiristic" and "positivistic" perspective. Frank Fischer, in particular, criticizes what he describes as the rational, technocratic and empiristic notion of policymaking. According to him, the relationship between knowledge and policymaking is a far more complex nexus implying meanings, values, and belongingness. Policy research has, therefore less to do with quantitative/qualitative and factual results than with discursive methods and argumentative processes of deliberation $[9,10]$.

This shows how policy analysis is a fairly new discipline, still in need of investigation into its specific character, definition, current challenges and future perspectives.

More specifically, are there any particular aspects effecting policy research for the government and its policies? What are the problems and opportunities for research in policymaking? What use do policymakers make of research results? These are just some of the many questions that the literature has not yet comprehensively addressed.

This paper does not aim to provide exhaustive explanations or describe actual cases, but to sketch out some questions and put forward some possible answers which more detailed analysis could explore. It centres on general and theoretical issues, referring especially to the risk, uncertainty and complexity of today's policy process situation; it also explores a possible role for policy research.

\section{Challenges and Constraints in a Complex Context}

The relation between research and policymaking encompasses various issues linked to the broader relation between science and politics. It is possible to divide them into two groups.

The first concerns the problem of the different ontological nature of research and politics. While the former (both in natural and social sciences) generally requires long-term developments, politics is played out over medium and short periods (the longest time span of policy decisions may consist only of a single legislature, four to five years). Elections follow one another frequently, and policymakers' career prospects are fluid and unstable; the political and institutional environment of decision-making does not fit well with long-term perspectives, analyses, and research. In other words, while research formulates previsions and scenarios based only on observation of past facts, politics is always projected toward the future-the next election. Therefore, policymakers may not adopt the best-responding solutions, those that research indicates, but rather those that are most likely to give positive returns-winning votes and staying in office.

A further difference is found in the conditions under which research and politics are carried out. The former may be done in terms of conceptual models or theoretical frameworks; yet the actual socio-political processes that policymakers must face may clash with these models. The concrete conditions of the actual environment on which policies impact can be totally different from those in which research is developed, due to variability and uncertainty as well as methodological pitfalls.

Lastly, there is divergence also in the approach to reality. Scientific knowledge is historically grounded on rationality and a-valutativity, whereas political processes and logic are necessarily partial and partisan. Sometimes, science produces paradigms; some other times, it is politics that generates them, maybe even partially, from scientific discovers or theories. There is the apparent paradox that policymakers depend on impartial research to make informed decisions, yet policymakers are by definition partisan actors, who operate not just according to party ideology but also personal objectives. On the other hand, researchers often ignore decision-making processes and the political context, not to mention public opinion on their own objects of study. Hence, attempts to conciliate the two positions may be unsuccessful.

A second set of issues is concerned with the political use of scientific knowledge. Since the very beginning, policymakers have tried to frame the development of science, for instance by setting its limits according to philosophical or religious views, and/or to use science for their purposes. On the other side, (some) scientists have strived for independence from politics and carried out their work disregarding, or indeed not knowing, the likely future political uses of their results. Furthermore, nowadays, in a democratic society, the role of science is more than ever at the centre of discussion. Scientific research is continually questioned and re-examined, on both the epistemic and ethical levels, by a public evermore informed about and interested in, for example, the issues of Genetically Modified foods and bioethics.

Nevertheless, this paper is concerned not so much with theoretical research, but rather with research developed for the purpose of policymaking. In particular, researchers who work for policymakers must face at least two environmental challenges, with weighty practical impli- 
cations: the uncertainty of the current world, in which new frontiers of science and technology may have both positive and negative overwhelming effects; and the complexity of the social and economic realms on which policies have to impact. It is to these two themes that we now turn.

\subsection{The Problems of Uncertainty}

The importance of risk and uncertainty in today's world has been widely discussed and recognized. On one side, the complexity of the social, environmental, and economic realms (see below) entails a continuously varying, hence uncertain, context for policymakers' decisions as well as the high risk that policies, once planned, decided, and implemented, will not fit the changing reality and thus will not deliver their intended results. On the other side, the tremendous advances that science and technology have made in recent years mean that virtually nobody - not even scientists themselves, let alone politicians - can predict in sufficiently safe terms what technical resources and practical conditions, in other words what kind of reality, new technologies and discoveries will bring about. Walker [11] defines this as "structural uncertainty" insofar as it:

"relates to the future structural elements of the world that are relevant for making policy, but are unknown and unknowable at the time of the analysis. But decisions have to be made in the face of structural uncertainty. (...) Any policy has implications for the future that actually occurs that was probably not examined in the course of the analysis and that are generally not revisited as the future unfolds. (...) In addition, if there are many plausible future scenarios, it may well be impossible to construct any single static policy that will perform well in all of them. (...)

Fixed policies can fail for particular scenarios because they fail to exploit opportunities that arise, ignore crucial vulnerabilities, or depend for their performance on critical assumptions that fail to hold. Assumptions about the nature of the world can simply prove to be untrue, other actors may take actions in response to the policy that undermine its utility, or exogenous events may critically change the conditions under which the policy must operate.”

As a result, "the political manipulation of uncertainty is now the focus of any relevant epistemology" [12], and uncertainty management is today acknowledged as crucial by both scientists and policymakers. In reality, uncertainty has been explicitly factored into policy analyses sixty years ago when Herbert Simon [13] introduced into the study of public administration (and organizational theory in general) the "paradigm of bounded rationality", which assumes that public decision-makers are not om- niscient, since human understanding of alternatives (in any decision-making environment) is necessarily imperfect. Given the uncertainty of goals and means that decision-makers have, any decision concerning an issue will not result in a rationally perfect result, but will rather consist of a "subjectively" rational solution, based on its appropriateness as understood by the decision-makers.

A first step to reduce uncertainty is to recognize that it comprises several dimensions, with different levels of importance, and that the tools for measuring and evaluating uncertainty so far developed are still at an embryonic stage [14]. Uncertainty exists in every phase of the policy process, from the framing of problems to the involvement of stakeholders. It regards not only the ecological, technological, economic, social, organizational, and political context of decision making, but also the technologies and resources available, the opinions of experts on the issues at stake, the theoretical models used in the analysis and its parameters, the data and their variability, the selection of indicators, the definition of problems and possible consequences of innovation, and the issues' ethical implications. Van der Sluijs and Craye [15] suggest some specific dimensions of uncertainty related to policymaking:

- the decisions on many issues must usually be made before final scientific evidence on them is available -uncertainty of information;

- the impact of errors due to wrong decisions is potentially high;

- the problematization of an issue, as well as of the indicators through which to measure it, is often characterized by value choices.

Friend and Jessop [16], moreover, assert that organizations (such as local governments) face "political uncertainty", referring to the need for value judgments as expressions of a clear political line in order to give effective responses. In addition, they define "uncertainty from interrelation and co-ordination" as related to the need for co-ordinating the choices of behaviour that different administrations, operating in connected fields, must take, given the interdependence existing between various sectors of public policies and the impact that the action of some institutions has on other institutions.

To recap, politicians must cope with risk and uncertainty daily, and usually strive to reduce it. Within the literature on policy analysis, Lindblom [17] is the first author to highlight that, given the uncertainties of the world, all-encompassing analyses and solutions - and underlying research — are bound to fail. He introduces the concept of incremental policies and incremental analysis, through which uncertainty can be reduced. The former consists of modifying outputs, and consequently, outcomes, gradually, step-by step; the latter is the process of 
analyzing policy problems one-by-one, instead of setting up synoptic analytical frameworks which can never be exhaustive and comprehensive. Lindblom rejects as "unrealistic" the assumption that policy solutions are necessarily rational. In fact policy decision is usually a compromise ("mutual adjustment" in his words) among all decision-makers — politicians, interest organizations, bureaucrats — that leads to "satisfying" solutions.

In broader terms, the most common strategy for uncertainty reduction is to seek safety and stability [18]. According to Ackoff [19], it is a fundamental human trait (hence shared by decision-makers) to seek stability as a means of reducing uncertainty. However, due to societal complexities, this is increasingly harder to achieve:

"Human beings seek stability and are members of stability-seeking groups, organizations, institutions, and societies. Their objective may be said to be "homeostasis", but the world in which this objective is pursued is increasingly dynamic and unstable. Because of the increasing interconnectedness and interdependence of individuals, groups, organizations, institutions, and societies brought about by changes in communication and transportation, our environments have become larger, more complex, and less predictable-in short, more turbulent.”[19]

Policymakers are notably very reluctant to change, since the consequences for policies, rules, alliances etc. are difficult to predict (that is, are uncertain) in a democratic system where office holders rely on voters' suffrage. According to Browne [18], policymakers must weigh demands and strategically select those policies that promise the best personal returns. Positive publicity regarding good policy also helps to enhance the pay-off and reduce uncertainty. Hence, to sum up, politicians' vulnerability [20] is an important variable to take into account when studying the policy process.

\subsection{The Reality of Complexity}

It has been widely recognized that contemporary societal context is characterized by an increasing interconnectedness and interdependence of individuals, groups, organizations, institutions, and societies [19]. 'Complexity' is the most-widely used term to describe this shift from vertical to horizontal relationships in our era" [21]. In historical perspective, Beer maintains that for many centuries horizontal linkages were not very important for the vast preponderance of human beings, except for the aristocracy for whom the ability to form coalitions and cement alliances was crucial for survival.

"The organizational quantum, a village in a feudal society or the subsidiary of a firm (...) obeyed the law up- wards and administered the law downwards. What the cousins were doing, which is to say organizational quanta at the same hierarchic level, was really of no concern" [22]. He argues that "perhaps the major organizational issue today could be called horizontal relevance."

This has come about through the interaction of a number of factors.

"Technology has facilitated the proliferation of individual variety and hence the complexity of society. Communication technology in particular (...) has facilitated the spread of horizontal networks, as a result of which, society has 'fairly suddenly become massively interactive" [21].

To summarize, horizontal links are a peculiar characteristic of today's complex society.

Other elements of complexity exist, and a comprehensive definition of it seems difficult. All attempts at definition acknowledge the multidimensionality of complexity, which is in fact signalled by the latin origin of the word, cum and plecto, which means the character of being interwoven. We can consider the following as dimensions of complexity:

- A complex society is where many distinct and heterogeneous components coexist: "there is increased differentiation with many more parts (identities) and sub-systems all relatively autonomous from each other and all potentially either mutually-enabling or mutually-inhibitory" [21].

- The presence of large quantities of information, originating from all these components, to process.

- Connectedness. These distinct components are nonetheless connected among themselves in such a way that it is hard to separate them (as they are indeed 'interwoven'). Thus, complexity implies also some form of reciprocal dependency among these components, in particular as regards information.

- Emergence. The term 'complexity' refers to phenomena and situations in which the distinct but connected parts produce an unexpected and uncalculated collective behaviour or effect. In other words, the interaction among social units may produce new proprieties that single components do not have by themselves (as, for example, is clearly shown in chemistry or physics).

- Self-organization. The units of complex systems may self-organize, first of all because each one communicates with the closest others, gets feedback from them and with them it can adopt collective behaviours.

To recap, complexity is not a synonym of chaos, perfect disorder, absence of rules and shared attitudes, nor is complexity necessarily a negative concept; however, it is clear that in complex systems action takes longer to effect, and many points of view have to be taken into account. 
Why is complexity so problematic for politics? Because complexity has altered the balance of traditional forms of domination and control. A thing is "complex" when it exceeds the capacity of a single individual to understand it sufficiently to exercise effective control [23]. The regulatory process has indeed been forced to increase its own complexity and variety relative to that of the environment. A highly fragmented and differentiated society "has led to the stretching of the arms of government to embrace as much as possible of the emergent but refracted civil society" [21].

"Initially, as societies increase in complexity, more networks are created among individuals, more hierarchical controls are created to regulate these networks, more information is processed, there is more centralisation of information flow, there is increasing need to support specialists not directly involved in resource production, and the like. The result is that as a society evolves toward greater complexity, the support costs levied on each individual will also rise, so that the population as a whole must allocate increasing proportions of its energy budget to maintaining institutions dedicated to coordination, centralization and control” [24].

"Continued investment in socio-political complexity reaches a point where the benefits of such investment begin to decline, at first gradually, then with accelerated force. Thus, not only must populations allocate greater and greater amounts of resources to maintaining an evolving society, but after a certain point, higher amounts of this investment will yield smaller increments of return" [21].

Beer [22] cites for example the growth in complexity of the tax code.

"The general levy is a low variety tax, and therefore easy to administer. Once we take account of individual circumstances, the variety goes up. Trying to match this variety, more and more regulations are introduced-until it is doubtful whether anyone can work out what is happening. A similar situation exists for the police, and even for less obvious social regulators existing within education, health and social welfare."

In a well-known vicious circle, the increasing societal complexity leads to a plethora of tax exceptions in the fiscal and legislative frameworks, which in turn fuels the growth of the bureaucratic apparatus to manage such exceptions, which need to be sustained by more taxes.

Fiscal and organizational costs are just an example; complexity and uncertainty are problematic for policymakers entails other critical issues for politics:

- while it is relatively simple to reduce knowledge to single aspects and distinct units, it is not easy to elaborate models to understand all facets of complex systems; multiple relations and interactions makes it hard to iso- late the effect(s) of a single variable: many variables can change simultaneously;

- political decisions impact on so complex a reality that frequently they may have unpredicted consequences. Policymaking cannot be exercised anymore in a direct, simple, linear and coherent way; it is likely to be interrupted, transformed, and deflected across a myriad refractory and reflexive surfaces of identity [21];

- complexity also makes for tougher policymaking because it is difficult to find solutions for something which is hard to understand: the product (or 'emergence') of the relations between societal units is often uncertain and unpredictable.

In this context, then, how is it possible to perform appropriate and effective policymaking? What kind of knowledge-and respective research — is needed to adequately take into account complexity and uncertainty?

To begin, it has to be noted that multiplication of research does not necessarily bring about a reduction of uncertainty. Uncertainties in the knowledge base, especially when expressed through the existence of different scientific opinions and/or divergent interpretations in the socio-political debate, mostly cannot automatically be solved through additional research or reduced through comparative evaluations of research results [15].

Moreover, as mentioned above, the outcomes of scientific research on society-as well as, incidentally, within science itself-are not a priori foreseeable. Social science does contribute to policy and practice, "but the link is neither consensual, graceful or self-evident” [25]. This implies that there are many risks of political nature in formulating conclusive evaluations on the basis of research activity.

As we have seen, a fundamental element of both complexity and uncertainty is information or the lack thereof. Selecting and providing accurate and reliable information, thus, is perhaps the primary objective of research. However, information is produced not only by researchers and certainly it is not held exclusively by politicians either. Practices of sharing information and processes of deliberation have become common, as we shall see later on. In fact, the overall trend of today's governance models is away from top-down forms of directive control to increased relative autonomy within society itself.

As a tentative answer to the above questions, we can assert the need for new control technologies and new modes of governance that aim to avoid conflict in the relations between system units, and to stimulate their self-organization, hence reducing the component of risk. Therefore, in this context we can hypothesize the need for three kinds of research:

- one related to the extent and character of relations between systemic units; 
- one focusing on the effects emerging from interaction between these units;

- and one centering on the environment of such relations, aimed at elaborating rapid process for reconsidering plans and styles of behaviour following changes in the environment.

To govern today's reality, thus, policymakers need a kind of research that takes into account the existing elements of complexity and uncertainty. It is also for this purpose that

"knowledge itself has been reorganized (...) with the result that interdisciplinary studies taken as a whole are now far more important to society than studies made within the classical disciplines" [22].

The second part of the paper focuses on the role of research in the policy cycle and relevant issues concerning its transformation in the contemporary context; the third part will illustrate some institutional and practical consequences.

\section{Researching for Policies: The Issues}

Having outlined why research is important particularly in today's context, characterized by the challenges of uncertainty and complexity, this part of the paper aims to sketch out a framework for the definition of the topic, identifying relevant variables and pointing out the critical practical problems.

\subsection{Research in the Policy Process}

Policymakers need (or at least they often claim to need) fresh, detailed and reliable information, as well as scientific insights and interpretations, to reduce to a minimum the uncertainty in which they have to take their decisions. Uncertainty assessment is today acknowledged to be fundamental by both scientists and politicians. Policymakers depend on research, which provides both the information and the tools for understanding it. Van der Sluijs and Craye [15] identify seven possible functions of research in relation to the policymaking process:

- identifying contexts and scenarios;

- providing ad hoc policy advice;

- assessing existing policies;

- evaluating proposed policies (including ex-ante impact evaluation), their objectives and instruments;

- recognizing and investigating new problems;

- identifying and evaluating possible solutions;

- providing counter-expertise.

Given all these possible utilizations and functions, research can intervene at almost any stage of the policy cycle [26] and have different functions.

\subsubsection{Problem Identification and Agenda-Setting}

The identification and definition of an issue with policy implications can be done by a variety of actors: politicians, bureaucrats, the mass media, interest groups, and experts. In this phase research is fundamental. On one side, policy actors can draw ideas and evidence from research in order to push their policy through. On the other side, researchers themselves may point out problems for the policymakers' attention. At this stage, research can play a specific role as it is in a better position to explore issues, themes and ideas which are not already included in the political perspective. While politicians and policymakers are confined to today's topics and consensus, researchers can work on identifying tomorrow's issues. Because of their distance from policy and practice, researchers can investigate wider sets of ideas, to draw scenarios, and challenge current thinking [27].

Agenda-setting is the inclusion of issues in the government's agenda. At this stage research can also contribute to identify the issue to be addressed and to evaluate whether there are initiatives and possible policies which are likely to be effective. This aspect can be investigated mainly through desk analysis (typically: literature reviews and comparative research). Another contribution of research is to explore contextual factors and consensus implications of the possible options; these tasks are generally achieved through interactive methods of research like surveys, interviews, and group discussions.

\subsubsection{Negotiation, Deliberation}

In contemporary systems of governance, non-institutional actors usually take part in some way to make decisions on public policies. Such involvement may take different forms that may be briefly classified in the scale: consultation $>$ involvement $>$ collaboration $>$ decisionmaking power. Research is important at this stage too, as it can provide an understanding of the views and interests at stake: "consultation exercises and market research are often used, alongside more formal research, to explore the views and priorities of key stakeholders and the public" [27].

\subsubsection{Decision Making}

After the selection of policy options and dialogue with stakeholders, policymakers make their decision; yet there are many factors at play of which research results are just one. As seen above, researchers and political actors have different goals, patterns of behaviour, timings and priorities; thus research may not be the only basis on which policies are adopted. Decision making is probably the stage where research is less likely to be used; at this point, the number of relevant actors decreases signifi- 
cantly; "when it comes time to decide on adopting a particular option, the relevant group of policy actors is almost inevitably restricted to those with the authority to make binding decisions” [26].

\subsubsection{Implementation}

Implementation is the stage when, after a decision has been taken, "things have to be done" in practice. In spite of their technical abilities, bureaucrats - the primary actors in the implementation of any public policy-often need external expertise and knowledge to set and use policy instruments, which only researchers can offer; notably because policymakers often identify (and announce) only the objectives and general settings of policies, while the precise tuning of instruments and intermediary goals are delegated to the experts.

The contribution of research is mostly to prepare guidance for those implementing a policy, providing them with knowledge and expertise related to the technical aspects and societal implications of the necessary actions to be put in place. At this stage, the relationship between policy and research is very closely developed in terms of time and places. Very often, research at this stage is "action research" - an activity where researchers support and "accompany" practitioners daily, shoulderto-shoulder. One of the interesting characteristics of this method is the fact that there is no final research report, but rather a continuous knowledge transfer which put the practitioners "in a position to integrate learning into their work as it emerges” [27].

\subsubsection{Feedback}

Performing ex-post policy evaluation means doing research and collecting new information for future policy decisions. Hence, the tools for policy evaluation are very important, although due attention is not always and not everywhere paid to them.

The function of policy research is to assess the implementation through a wide range of different possible approaches, according to the kind of policy and the needs of policymakers. Evaluation requires very robust methods of analysis, but also, at the same time, a clear understanding and awareness of the intentions, objectives and targets to be evaluated. Indeed, many problems stem from the lack of clarity regarding the outputs/outcomes to be measured and evaluated.

Another decisive aspect of evaluating effectiveness is the difficulty in measuring outcomes. This is particularly true in many social interventions "which are only really understood by those experiencing them" [27].

It is worth noticing that the process of policymaking is not a linear one. In fact, "policy decisions often accrete through multiple disjointed steps" [28] and the influence of policy research on policymaking cannot be primarily conceived as a direct, punctual and immediate contribution to single issues. Researchers wishing to find such a linear relationship, with decisions taken on the basis of a consideration of their findings, will be almost always disappointed. This does not mean that research is ignored; it means rather that utilization of research is a more pervasive phenomenon. "Officials absorb a great deal of research knowledge through informal routes” [28] and in the medium and long term researchers working closely and constantly with practitioners can contribute in many indirect ways in giving information, introducing new ideas, proposing new terms, etc. which gradually become part of policymakers' sets of reasoning.

Notwithstanding this, it is true that research utilization remains, in many respects, poor [29]; and researchers should try to overcome this lack of utilization. Burton [30] suggests four opportune developments which researchers should work towards to make their findings more utilizable:

1) a constant orientation towards customers' needs rather than towards their own preferences;

2) an adequate investment (of time) for a greater dialogue with policymakers;

3) a proper style of communication, presenting their findings "clearly, concisely and coherently" [30] while avoiding specialized jargon;

4) a greater attention to the quality of their research.

These aspects remain permanent and valid suggestions even when policy research is called to play a new role in many respects, because of the significant transformations affecting policymaking, due to the increasing amount of complexity and uncertainty we are facing. The following paragraphs will try to illustrate some of the dimensions of these transformations.

\subsection{Scientific Advice in a Risk Society - Challenge for Democracy}

In a "risk-society" only some issues can be settled with purely scientific advice. Risks themselves are not all the same. Technical innovation and the development of an increasingly participatory society pose new kind of uncertainties and dialectical tensions. Recently Bijeker et al. [31] have proposed a quite effective framework of 4 different typologies of "risk":

- "simple"-there is uncertainty, although all knowledge is, in principle, available;

- "complex"-knowledge elements are available, although controversial;

- "uncertain" - the problem shows a structural lack of scientific knowledge, although a sufficient degree of consensus characterizes the issue; 
- "ambiguous"-not only is scientific knowledge structurally unable to fill the gap, but there is no consensus and even societal dominant values are challenged.

Scientific advice can play a decisive role only in some of these cases, typically those situations where the risk problem is "simple" or "complex". In all the other cases, where the risk problem is either "uncertain" or "ambiguous", scientific advice has to be adequately integrated by both stakeholders' involvement and societal debate.

Bijker et al. [31] argue for a combination of technical expertise with societal participation. In a modern society, scientific bodies fully comply with their own democratic responsibility when (and if) on one side they guarantee the specific contribution of scientists-as long as the myth of objectivity of standard, normal science is overcome by a constructivist perspective-and on the other side when they recognize and give room to other forms of knowledge and experience (as long as any coordination work of forming ad hoc committees is adequate).

Technocracy is a myth. Normal science and empirical perspectives have been shown to be limited, although a proper epistemology, a precise and adequate methodology of involvement of other actors still needs to be defined and shared in practice.

Increasingly, policymaking is open to the participation of non-institutional actors. The term 'governance' is now widely used to describe new arrangements of policy definition, deliberation and decision which include social and private partners of the government. Deliberative venues have been set up in virtually all policy sectors, notably at the sub-national level, and many argue that, in a complex society, the open and transparent consultation between government and societal partners should take place not only in the phase of elaboration of policy outputs, but also at the beginning of the process, in identifying needs and issues to be addressed.

\subsection{New Strategies: Post-Normal Science, Adaptive Policymaking, Argumentative Turn}

In these deliberative arenas new problems, information, perspectives - and hence new policy solutions and options-may emerge from stakeholders, especially when they have direct grassroots expertise and develop their own research and studies. This learning process may strengthen and enhance the results and quality of initial research, not to mention possibly enhancing the legitimacy and support of the policies, provided the partners actively participate and do not limit their role to merely offering and receiving information-which would not open the debate to new solutions but rather close it. An important feature to understand any policy process is thus to identify which actors possess the crucial and updated information and offer added value to the process.

Yet the deliberative stage may also lead to the rejection of the findings of research and, instead of consensus, dissent and divergences could emerge among the actors (researchers, interest groups, politicians, bureaucrats) on various grounds:

- ideological (here lie the deepest and widest divisions);

- on the issue definition and the objectives policies should pursue;

- on the technical solutions proposed to problems;

- on previous or possible policy results;

- on the fairness of the policy process.

Moreover, some stakeholders can award or run independent research, notably when they have an internal or affiliated research structure, from which they can support their own political and social objectives and even challenge official results.

When the deliberation phase is inclusive, the policy options eventually selected may be different from those initially foreseen or suggested by researchers.

"In a policy process, separate visions may well come into conflict, and some stakeholders may even deny the legitimacy of the commitments and the validity of the perceptions of others." [32]

Ulrich Beck's concept of 'reflexivity' [33,34] seems relevant here:

"Reflexivity refers to a state and/or an attitude, created by an ensemble of processes, events, actions and measures, through which what is mostly accepted and not questioned is made the subject of study, discussion and deliberation leading to more openness, more possibility for societal debate and dialogue between policy, science and involved groups, enabling the construction of alternative policies or lines of action. Through reflexivity the content of current policy processes, including the problem definitions and supporting methodologies and approaches, as well as the patterns of interaction and the rules governing these interactions, are openly discussed" [15].

In other words, Beck underlines the importance of a constellation of self-confrontation ('reflex') to open the way for political, public and academic reflection on policymaking. The aim is to be open to all possibilities for the achievement of the best policy solutions.

Participation in policymaking offers another added value, insofar as it makes overcoming the limits of experts' contributions easier. These, in fact, are usually presented as objective, yet they are necessarily framed according to the intentions of the experts themselves. The non-expert can challenge the information provided 
by experts and can bring into the debate those themes and issues that the experts may have neglected. It appears indeed important to build a framework for the discussion which has to do not just with issue contents, but also with the definition itself of the issue. In other terms, uncertainty today characterizes not only the context of decision-making but also the contributions by experts who usually focus on specific measures and outcomes and do not contemplate the complexity of the universe of subjects and relations.

To sum up, deliberative practices may be valid tools for:

- building a shared framework for the issues to be analyzed in their multiple dimensions;

- expanding the initial knowledge on the issues;

- creating consensus on decisions taken and methods to be followed;

- promoting new networks of communication, exchange and trust between social and institutional actors.

This last aspect seems relevant notably because the public increasingly lacks confidence in scientific institutions.

Some observers have put forward the concept of 'post normal science' in this respect. Funtowicz and Ravetz argue that the:

"risk problems have to a large extent been created by the practice of normal, puzzle-solving science and technology. Scientists and engineers who always thought that their work was purely beneficial to humanity, either directly or indirectly, now discover new problems thrown up by their past successes. Worse, their training and their inherited approach do not equip them for the solution of the problems directly associated with their work." [12] "The problems of risks, both technological and environmental, have structural features that illustrate the inadequacy of traditional forms of problem solving. In these practices, decisions must be made involving the distribution of costs and benefits to different interests on the basis of future contingencies that are unknown and unknowable" [12].

Thus, the newer risk problems need a form of practice that includes, complements, and goes beyond applied science and professional consultancy.

"In this way these issues are provided with direction, quality assurance, and also the means of reaching a consensual solution to policy problems in spite of their inherent uncertainties” [12].

In such problematic situations:

"typically facts are uncertain, values in dispute, stakes high, and decisions urgent. Because applied science and professional consultancy are inadequate, something extra must be added onto their practice which bridges the gap between scientific expertise and a concerned public. This is post-normal science, comprising a dialogue among all the stakeholders in a problem, regardless of their normal qualifications or affiliations. For the quality assessment of the scientific materials in such circumstances cannot be left to the experts themselves; in the face of such uncertainties, they too are amateurs. Hence there must be an extended peer community, and they will use extended facts, which include even anecdotal evidence and statistics gathered by a community. (...) we envisage a democratization of science, not in the sense of turning over the research labs to untrained persons, but rather bringing this relevant part of science into the public debate along with all the other issues affecting our society.” [12]

"As the debate develops from its initial phase, positions are clarified and new research is stimulated. Although the definition of problems is never free of politics, an open dialogue ensures that such considerations are neither one-sided nor covert. (...) as new research eventually introduces new facts, the issue becomes more amenable to the approach of professional consultancy” [12].

Alongside this approach, Walker [11] elaborates the notion of 'adaptive policymaking' as a tentative response to the challenges of uncertainty and complexity which nowadays undermine the effectiveness of most policies. He explains this approach in the following terms:

"When events occur that invalidate some of the underlying assumptions of a policy, the policy may remain unchanged for a long time or policymakers may scramble to quickly develop new policies. The suggested 'adaptive' approach allows policymakers to cope with the uncertainties that confront them by creating policies that respond to changes over time and that make explicit provision for learning. It views uncertainty as something to be qualitatively understood in order to manage the timing of critical decisions and to develop robust policies. And it is continuously making use of new information to resolve the original uncertainties over time. (...)

For many problems, it is likely that the uncertainties that confront planners will be resolved over the course of time by new information. (...) Thus, policies should be adaptive-devised not to be optimal for a best estimate future, but robust across a range of plausible futures. An adaptive policy would include a systematic method for monitoring the environment, gathering information, implementing pieces of the policy over time, and adjusting and re-adjusting to new circumstances. The policies themselves would be designed to be incremental, adaptive, and conditional. (...)

The first step in the adaptive policymaking process is a 'stage-setting' exercise designed to make policy goals explicit, develop a clear set of options, and construct a 
definition of policy success that makes operational sense.

Successive steps in the process are:

- assemble the structure of the policy;

- identify key uncertainties and vulnerabilities of the policy;

- separate actions to be taken now from those that can or should be deferred until more information becomes available;

- develop signposts for monitoring changes in the world" (in order to be certain that the underlying analysis remains valid, that implementation is proceeding on schedule and according to expectations, and that necessary policy corrections or additional actions are taken in a timely and effective manner) "and triggers for contingency plans;

- establish limits to the validity of the analysis that, once violated, should lead to a reassessment of the policy."

Lastly, in the implementation phase actions are carried out to either correct the policy, on the basis of new information, or defend it.

"Developing and implementing adaptive policies will not be easy. There are significant legal, political, and analytic barriers to be overcome. The legal and political barriers are likely to be the hardest to overcome. Existing laws have been built up over the years to support the current approach to policymaking and policy execution. The organization and operation of existing institutions, both governmental and non-governmental, are based on the current paradigm” [11].

The reality where policy choices are taken is complex, so the relationship between knowledge and policy is intricate.

A third paradigm to be considered is called "the argumentative turn” proposed by Frank Fischer [9], who offers a comprehensive critique of what he describes as the rational technocratic and empirical notion of policymaking. In Fischer's view, the positivistic approach tends to consider the problem of implementation as a matter of reaching a certain degree of empirical knowledge. Science (mainly empirical and quantitative) would provide elements to fill the gap between problem and solution: tested and replicable results would give generalised knowledge applicable to a range of policy problems in different political contexts. The result is a strong emphasis on rigorous and quantitative analysis and the "myth" of the objective separation between facts and values.

Fischer argues that in fact, in a complex risk-society, values and meanings are an essential part not only of the societal context, but also (and as a consequence) of the policy analysis scope. In order to be effective and usable, policy research should encompass and incorporate meanings and values; and must show that it is capable of replicating and illustrating the different dynamics and perspectives included in the matter; in a nutshell, that it can deal with the discursive dimensions of societal problems.

Differently from the fixity proposed by the normative and positivistic approach, policy analysis becomes a process of argumentation.

"The argumentative turn starts from the recognition that multiple perspectives are involved in the interpretation and understanding of social and political reality and the competing definitions of policy problems to which they give rise. Toward this end, an argumentatively- oriented deliberative policy analysis seeks to disarm epistemologically the one-dimensionality objectivity of conventional policy analysis, often advanced as value- neutral scientific policy analysis” [10].

It has been rightly noted that Fisher

"proposes a new approach to policy analysis that combines an epistemological preference to constructivism with a very clear ideological stance about the purpose of policy analysis” [30].

In doing so, policy research fosters the policy process to become a sort of continuous dialogue and public debate, therefore improving participation in democracy. Policy research should not serve "intentionally or unintentionally to facilitate and bolster bureaucratic governance” nor "as an ideology that masks elite political and bureaucratic interests"; on the contrary, it should

"provide access and explanations of data to all parties, to empower the public to understand analyses, and to promote serious discourse" [9].

These are theoretical approaches that design new ways of making policies and policy analysis aimed at adapting to (and reducing the negative potentialities of) risk and complexity.

In conclusion, this paper has provided a critique of the main issues and challenges concerning the matter of complexity, with particular respect to policymaking and research for policymaking. It has not given answers, its goal being to offer some questions to be addressed and discussed by actors in specific situations. The problems and opportunities of the uncertain and complex environment in which and for which research is carried out; the varying functions research takes on in the different phases of the policy process; the role of scientific advice in contemporary democracy, the innovative approaches of post-normal science, adaptive policymaking and argumentative turn. Future work in this field should concentrate on all these issues, and all seem relevant for defining the very scope and nature of research aiming to provide policymakers with information useful (and usable) for adopting the best solutions to policy issues. 
The only definitive conclusion we propose is that policy analysis is destined to play a decisive role in contemporary democracies. Complexity and uncertainty challenge political power to take decisions on difficult/ complex matters. The traditional linear process no longer works, neither for the democratic policy cycle, nor even for scientific advice and policy analysis. New knowledge is required, where meanings, participation, and deliberative processes are substantial parts of decision making.

Returning to our initial metaphor, in contemporary democracies Aristotle alone is not sufficient; technical and scientific professionals have to rely on many different actors and resources to conduct policy research; knowledge for policy results from a combination of many skills, competences, methods, value systems and beliefs. Policy analysis is, in fact, a sort of art or craft developed through a set of both traditional and non- traditional competences.

\section{References}

[1] H. Bochel and S. Duncan, "Making Policy in Theory and Practice,” Policy Press, Bristol, 2007.

[2] P. Lerner and F. Lasswell, "The Policy Orientation," University of Chicago Press, Chicago, 1951.

[3] N. Caplan, "The Two Communities Theory and Knowledge Utilization,” American Behavioral Scientist, Vol. 22, No. 1, 1979, pp. 459-470.

[4] C. T. Hallers-Tjabbers, "Maritime Shipping and the Environment,” In: A. G. Pereia, M. A. Cabo and S. Funtowicz, Eds., The Potential of Science and Scientists to Assist in Policy Planning for the Environment and in Raising Public Awareness, 2003, pp. 29-30.

[5] B. Wittrock, "Social Knowledge and Public Policy: Eight Models of Interaction,” In: P.Wagner, C. H. Weiss, B. Wittrock and H. Wollmann, Eds., Social Sciences and Modern States: National Experiences and Theoretical Crossroads, Cambridge University Press, 1991, pp. 337339.

[6] C. Weiss, "Using Social Research in Public Policy Making,” Lexington-Heath, Lexington Mass, 1977.

[7] J. Bellamy, "Linking Science, Policy and Local Governance: Moving beyond 'Talk the Talk' through Community-Based Research,” In: A. G. Pereia, M. A. Cabo and S. Funtowicz, Eds., 2003, pp. 14-15.

[8] C. E. Lindblom and D. K. Cohen, "Usable Knowledge: Social Science and Social Problem Solving,” Yale University Press, New Heaven, 1979.

[9] F. Fischer, "Reframing Public Policy: Discursive Politics and Deliberative Practices,” Oxford University Press, UK, 2003.

[10] F. Fischer, J. G. Miller and M. Sidney, "Handbook of Public Policy Analysis: Theory, Politics, and Methods,” Taylor \& Francis Group, London, 2008.
[11] W. Walker, "Adaptive Policies: An Approach for Dealing with Structural Uncertainty in Public Policymaking," Delft University of Technology, Leiden, 2001.

[12] S. Funtowicz and J. R. Ravetz, “Three Types of Risk Assessment and the Emergence of Post-Normal Science in S. Krimsky,” In: D. Golding, Eds., Social Theories of Risk, Greenwood, Oxford, 1992, pp. 251-273.

[13] H. Simon, "Administrative Behavior: A Study of Decision-Making Processes in Administrative Organizations," Free Press, New York, 1947.

[14] J. P. van der Sluijs, "Quicksandy Knowledge Bases,” In: A. G. Pereia, M. A. Cabo and S. Funtowicz, Eds., The Need for Guidance for Dealing with Uncertainty, Assumptions and Value Commitments in Environmental Assessment, 2003, pp. 8-9.

[15] J. van der Sluijs and M. Craye, "Uncertainty Assessment," in Joint Research CentreEuropean Commission, Knowledge Assessment Methodologies Fall School, Note Book, 2005, pp. 58-67.

[16] J. K. Friend and W. N. Jessop, "Local Government and Strategic Choice: An Operational Research Approach to the Process of Public Planning,” Tavistock Publications, London, 1969.

[17] C. E. Lindblom, "The Intelligence of Democracy Decision Making Through Mutual Adjustment," The Free Press, New York, 1965.

[18] W. P. Browne, "Cultivating Congress: Constituents, Issues, and Interests in Agricultural Policymaking," University Press of Kansas, Lawrence, 1995.

[19] R. L. Ackoff, "Creating the Corporate Future: Plan or be Planned for,” Wiley, New York, 1981.

[20] S. Bartolini, "Electoral and Party Competition: Analytical Dimensions and Empirical Problems,” In: R. Gunther, J. R. Montero and J. J. Linz, Eds., Political Parties. Old Concepts and New Challenges. Oxford University Press, 2002, pp. 84-110. http://www.si.umich.edu/ICOS/Rynes pdf

[21] P. A. Stokes, "Metaphorum on Cybernetics and Governance," From Government to the Management of Complexity: The Cybernetics of Governance, The University of Sunderland, 2004.

[22] S. Beer, "Platform for Change," John Wiley \& Sons, London, 1975.

[23] W. L. Livingston, “The New Plague,” FES Publishing, Bayside NJ, 1985.

[24] J. A. Tainter, "The Collapse of Complex Societies," Cambridge University Press, UK, 1988.

[25] M. Rein, “Social Science and Public Policy,” Penguin, Harmondsworth, 1976.

[26] M. Howlett, M. Ramesh and A. Perl, "Studying Public Policy, Policy Cycles and Policy Subsystems,” Oxford University Press, Toronto, 2009.

[27] A. Boaz and S. Nutley, "Evidence-Based Policy and Practice,” Public Management and Governance, London: Routledge, 2009, pp. 327-344.

[28] C. Weiss, "Policy Research in the Context of Diffuse Decision Making," The Journal of Higher Education, Vol. 
53, No. 6, 1982, pp. 619-639.

[29] S. Nutley and I. Walter, et al., "From Knowing to Doing: A Framework to Understanding the Evidence into Practice Agenda,” Evaluation, Vol. 9, No. 2, 2003, pp. 125148.

[30] P. Burton, "Modernising the Policy Process: Making Policy Research More Significant?” Policy Studies, Vol. 27, No. 3, 2006, pp. 173-195.

[31] W. E. Bijker, R. Bal and R. Hendriks, "The Paradox of Scientific Authority," Cambridge Mass: The MIT Press, 2009.

[32] S. Funtowicz, "Post-Normal Science. Science and Governance under Conditions of Complexity," Institute for the Protection and Security of the Citizen, London, 2002.
[33] U. Beck, "Risk Society: Towards a New Modernity," Sage, London, 1992.

[34] U. Beck, "The Reinvention of Politics. Rethinking Modernity in the Global Social Order," Cambridge: Polity Press, UK, 1996.

[35] M. Craye, S. Funtowicz, J. P. van der Sluijs, “A Reflexive Approach to Dealing with Uncertainties in Environmental Health Risk Science and Policy,” International Journal of Risk Assessment and Management, Vol. 5, No. 2-4, 2005, pp. 216-236.

[36] M. Mintrom, "People Skills for Policy Analysis," Georgetown University Press, Washington DC, 2003. 